\title{
Erratum to: System Dynamics Evaluation of Climate Change Adaptation Strategies for Water Resources Management in Central Iran
}

\author{
Alireza Gohari ${ }^{1} \cdot$ Ali Mirchi $^{2} \cdot{\text { Kaveh } \text { Madani }^{3}}^{3}$
}

Published online: 19 May 2017

(C) Springer Science+Business Media Dordrecht 2017

\section{Erratum to: Water Resour Manage \\ DOI 10.1007/s11269-017-1575-Z}

The original article includes the wrong version of Fig. 10, which illustrates the Zayandeh-Rud basin's development archetype with impacts of climate change on the water resources system. We have provided the correct version of Fig. 10 to rectify the oversight.

The online version of the original article can be found at http://dx.doi.org/10.1007/s11269-017-1575-z

Kaveh Madani

k.madani@imperial.ac.uk

Alireza Gohari

alirezagohari@gmail.com

Ali Mirchi

amirchi@utep.edu

1 Department of Water Engineering, College of Agriculture, Isfahan University of Technology, Isfahan, Iran

2 Department of Civil Engineering and Center for Environmental Resource Management, University of Texas at El Paso, El Paso, TX 79968, USA

3 Centre for Environmental Policy, Imperial College London, London SW7 2AZ, UK 


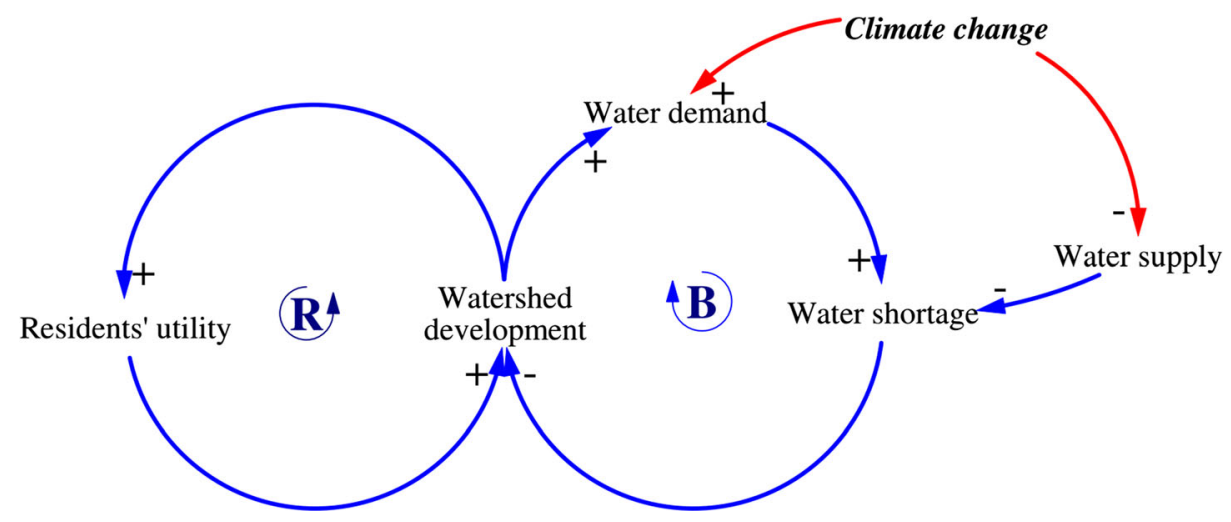

Fig. 10 The Zayandeh-Rud River basin's development archetype with impacts of climate change on the water resources system 